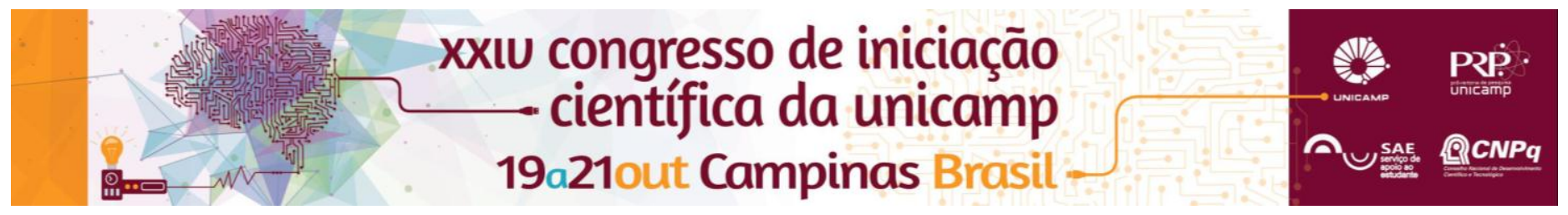

\title{
Identificação de células mesenquimais indiferenciadas nos tecidos periodontais durante a evolução da doença periodontal experimental.
}

\author{
Larissa M. Aguiar*, Mércia J. da S. Cunha, Cristiane R. Salmon, Viviene S. Barbosa, Karina G. S. Ruiz
}

\begin{abstract}
Resumo
60 ratos machos (Rattusnorvegicus, albinus, Wistar), receberam ligadura de algodão na região subgengival de um dos primeiros molares inferiores (lado teste) para indução da doença periodontal experimental. $O$ primeiro molar contra-lateral foi utilizado como controle (boca dividida) Após os períodos de 3, 7, 14 e 21 dias de indução da doença periodontal, 40 animais foram eutanizados, e as amostras de 10 animais por período foram fixadas e submetidas ao procedimento histológico de rotina para avaliação histométrica e ensaio de imunohistoquímica para os marcadores de fenótipo mesenquimal indiferenciado (CD146, CD105 e CD166). Os mesmos ensaios foram realizados em outros 20 animais que receberam tratamento periodontal básico após 21 dias de indução da doença. Esses animais foram eutanasiados $3(n=15)$ e $7(n=15)$ dias pós-tratamento para realização de análise histométrica e imunohistoquímica.
\end{abstract}

\section{Palavras-chave:}

Doença periodontal, células mesenquimais indiferenciadas, regeneração periodontal.

\section{Introdução}

Além de condições relacionadas ao paciente, o ponto chave para o sucesso da terapia regenerativa depende do recrutamento e proliferação de células mesenquimais indiferenciadas remanescentes na área do defeito, acompanhada pela subsequente diferenciação em osteoblastos, cementoblastos e fibroblastos, e pela síntese de componentes da matriz tecidual. Até o momento, não existem evidências concretas a respeito da distribuição natural destas células nos tecidos periodontais. O presente estudo teve como objetivo avaliar o padrão de distribuição das células mesenquimais indiferenciadas nos tecidos periodontais e verificar sua distribuição durante a evolução da doença periodontal experimental e póstratamento periodontal básico.

\section{Resultados e Discussão}

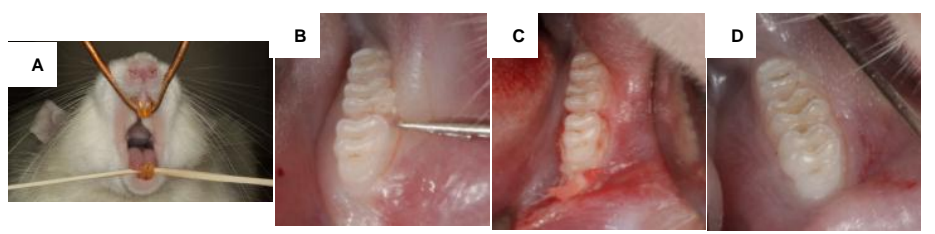

Figura 1. A indução da doença periodontal experimental. A. animal posicionado no aparato de Doku modificado e maxilares mantidos abertos por meio de bandas elásticas presas aos incisivos. B. espaçamento dos dentes com auxílio de um espaçador endodôntico modificado introduzido entre $01^{\circ}$ e $2^{\circ}$ molares inferiores. C. inserção de ligaduras de algodão unilateral na região subgengival do primeiro molar inferior D. 1ำ molar contralateral não recebeu ligadura (boca dividida).

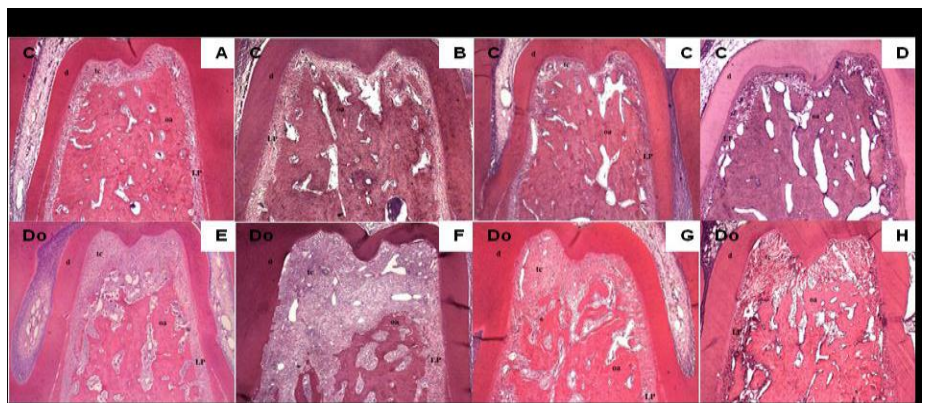

Figura 2. Fotomicrografias ilustrando área do ligamento periodontal ou reabsorção óssea alveolar na região de furca dos 1 os molares em aumento de $50 x$ (5x objetiva e 10x ocular) durante os períodos experimentais de $3,7,14$ e 21 dias de indução da doença peridonta. $\mathrm{C}=$ controle e $\mathrm{Do}=$ Doença.

Tabela 1. Distribuição das médias e desvios-padrão das medidas de reabsorção óssea em $\mathrm{mm}^{2}$ segundo o período de indução da doença periodontal.

\begin{tabular}{|l|l|l|l|l|l|}
\hline Grupos & 3 dias & 7 dias & 14 dias & 21 dias & P (K-Wallis) \\
\hline Controle & $0,07 \pm 0,01 \mathrm{~A}$ & $0,07 \pm 0,01 \mathrm{~A}$ & $0,06 \pm 0,007 \mathrm{~A}$ & $0,06 \pm 0,009 \mathrm{~A}$ & 0,2 \\
\hline Doença & $0,15 \pm 0,03 \mathrm{Ba}$ & $0,29 \pm 0,11 \mathrm{Bb}$ & $0,18 \pm 0,07 \mathrm{Ba}$ & $0,14 \pm 0,03 \mathrm{Ba}$ & 0,0007 \\
\hline p (Test t) & 0,0008 & 0,002 & 0,0001 & 0,0001 & \\
\hline
\end{tabular}

Letras maiúsculas distintas representam a diferença intergrupo (controle versus doença) pelo Test $t$ Letras minúsculas distintas representam a diferenç intragrupo ( 3 versus 7 versus 14 versus 21 dias) identificadas pelo Teste de Kruskal-Wallis com análise de comparação pelo método Student-Newman-Keuls. vertical diferem

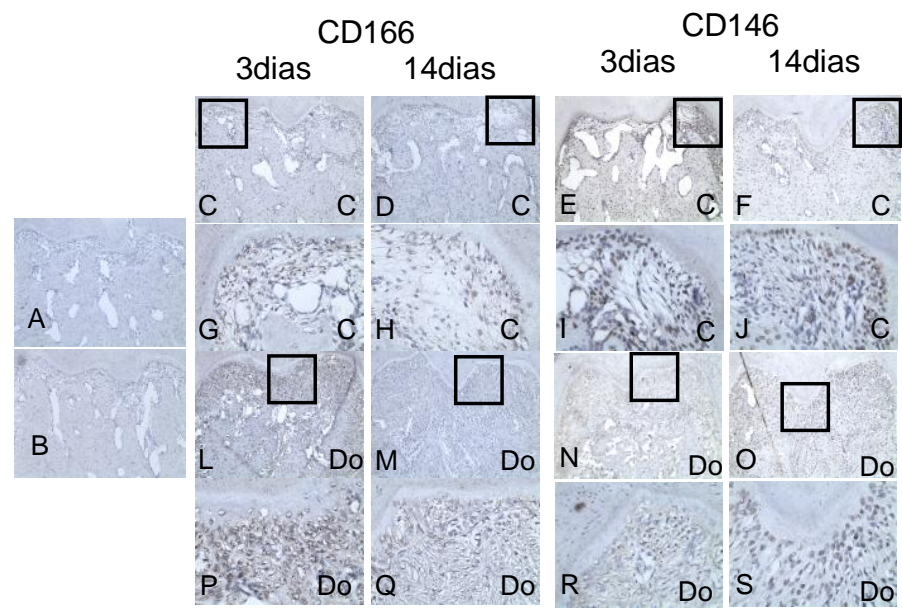

Figura 3. llustrações representativas das imunomarcações para o antígeno de superfície CD166 (ALCAM) e CD146 (Mel-CAM). A,B. Controles negativos da reação. C-J. Grupo controle (sem indução de doença periodontal). L-S. Doença periodontal induzida pelos períodos de 3 e 14 dias. Cortes histológicos em aumento de 100x (objetiva de 10x e ocular de 10x). C-F; L-O. Cortes histológicos em aumento de 400x (objetiva de 40x e ocular de 10x) G-J; P-S.

\section{Conclusões}

Até o momento podemos concluir que as células mesenquimais indiferenciadas estão localizadas na região do ligamento periodontal e de reabsorção óssea, na região perivascular e e nos osteócitos.

\section{Agradecimentos}

PIBIC,CNPq (480157/2013-8)

${ }^{1}$ Seo, B.M., et al., Investigation of multipotent postnatal stem cells from human periodontal ligament. Lancet, 2004. 364(9429): p. 149-55. 